\title{
Protection of the Rights and Interests of Scattered MinZu in Chinese Cities
}

\author{
Hua Liu \\ Law School \\ Sichuan Unviersity \\ Chengdu, China
}

\begin{abstract}
In the process of urbanization, many MinZu populations have moved from the original countryside into the cities for job. They become from the settlers into diasporas. Their concept, lifestyle etc. is caused significant damage because of City is different from the country's way of life that works system and surrounding environment. It is a realistic problem how to ensure that this part of the city's scattered MinZu can remain and happy to do something. And the current urban MinZu work needs to pay attention to these problems. It is undoubtedly an inevitable choice to formulate relevant laws and perfect working mechanism.
\end{abstract}

Keywords—scattered; MinZu; rights

\section{INTRODUCTION}

According to the 2009 "China's Ethnic Policy and Common Prosperity and Development of All Ethnic Groups," the scattered MinZu population has more than 30 million in 2009 years.[1] Statistics show that at present, China has more than 10 million ethnic minority migrants.[2] In the future, with the continuous progress of urbanization, The scattered MinZu population will be more and more. Many rural MinZu groups will be into the city from the village for job and living. How to protect the relevant rights and interests of this part of the people is an important part of the construction of China's MinZu law.

\section{OVERVIEW OF SCATTERED MINZU IN CITIES}

Urban scattered MinZu mainly refers to the lack of regional autonomy in the city to establish self-government organs of MinZu. [3] The scattered MinZu in cities have their own characteristics compared with those of rural MinZu. First, modern information technology is easier to let them live together. The city's population aggregation effect determines that the city's information is disseminated rapidly and spread, and that any news about MinZu is likely to spread out in a short time. In the Internet age, people's information dissemination channels, transmission channels and the transmission speed are greatly beyond the previous. They communicate more efficiently. Secondly, the scattered MinZu in the city can be divided into two categories: the resident population of MinZu and the floating population of

Fund Project: State Ethnic Affairs Commission 2017 MinZu research project: The Dilemma of MinZu Community Development in The National Park Construction and Legal Countermeasures(2017-GMB-028)
MinZu. Many Chinese cities have the scattered MinZu population.After a long period of development, this part of the people has long been integrated into the city life, and become an ordinary citizen. This part of the people generally agree with the city life, and high cultural quality, have a greater impact in their MinZu group. It is very important to stabilize and unite this MinZu by guaranting their rights and interests. The migrant MinZu workers generally like to live together. And most of them are less knowledge and have narrow employment. At the same time, Their MinZu identity is stronger than others. Once, they find that certain things may jeopardize their interests, they may join forces to make trouble by the excuse on hurting their MinZu feelings. The result is that the originally very simple event has become complicated due to ethnic issues. For example, in the southeastern province from 2008-2010, more than $80 \%$ of ethnic conflicts occurred in cities. [4]

\section{THE MAIN CONTENT OF THE RightS OF SCATTERED MINZU GROUPS IN CHINESE CITIES}

China has always attached importance to the protection of the rights and interests of scattered-minority $\mathrm{MinZu}$ groups. The "Common Program of the Chinese People's Political Consultative Conference" promulgated in 1949 stipulated: "Where there is a place where all MinZu groups are living and within the $M i n Z u$ autonomous region, all $\mathrm{MinZu}$ groups should have a considerable number of representatives in the local organs." In 1952, the State Council Promulgated the Decision on the Protection of All scattered MinZu into the Equal Rights of MinZu, which clearly stipulates the political right, the right to vote and the right to be selected, and to maintain or reform their lifestye, peoples religious rights and customs and customary rights of scattered $\mathrm{MinZu}$ groups,and the use of the MinZu language and other aspects of the right to enjoy the relevant rights.The subsequent "electoral law" has made specific provisions to ensure that the number of representatives of the $\mathrm{MinZu}$ groups's Congress. On August 29, 1993, the State Council promulgated The Regulations on Urban MinZu Work. Its legislative purpose is "In order to strengthen the urban $M i n Z u$ work, protect the legitimate rights and interests of urban MinZu groups, promote the needs of urban MinZu groups and adapt to the economic and cultural development." [5] The Ordinance is the main legal basis for 
the protection of urban scattered MinZu groups. Its main contents are:

- We should strengthen the leadership of urban MinZu work. The leadership of urban MinZu work is reflected in all aspects.For examples, in the preparation of $\mathrm{MinZu}$ economic and social development plans, we should consider to give to the economic and cultural needs of local MinZu groups and appropriate financial support. At the same time, not only the representatives of MinZu groups in the National People's Congress can guarantee their national economic and social development plans to reflect their requirements, but also in accordance with the provisions of government personnel, the relevant special MinZu cadres should manage MinZu affairs. At the same time, in the relevant street offices, communities and directly for the production and living of $M i n Z u$ departments or units, there should equipped with an appropriate number of $\mathrm{MinZu}$ cadres. The government should pay attention to the training of $M i n Z u$ cadres. The order of training the MinZu cadresis is to protect the interests of minorities $M i n Z u$ in the decision-making and implementation stage.

- The protection of urban MinZu labor and education rights. The government should pay attention to cultivating the professional and technical personnel training of MinZu groups. In the enterprise recruitment, we should encourage enterprises to employ $\mathrm{MinZ} u$ groups. For small $\mathrm{MinZu}$ enterprises and self-employed households, the government should give support and preferential treatment in loans and taxes so as to reduce its operating costs. The government enacts laws that protect ethnic minorities such as halal food. In the education, the government develop policies to improve the quality of MinZu Teachers,such as MinZu Talents Program. The government should run various ethnic schools.In the aspects of funding and teachers with the MinZu schools (classes), government should give appropriate care and develop various vocational, technical and adult education according to the characteristics of local MinZu groups. MinZu adolescents in the stage of compulsory education should be given appropriate care in the scores.

- The protection of the gustom of urban MinZu groups. First the public servants and other citizens should respect the customs of MinZu groups in the publicity, reporting, literary and artistic creation, film and television production. We should pay special attention to respect for $\mathrm{MinZu}$ customs, religious beliefs and $\mathrm{MinZu}$ feelings. In the catering industry, especially in the production of halal food, we should respect the customs of Muslim groups, and it need equip with a certain percentage of the consumption of halal food workers and management cadres. The transport vehicles, measuring instruments, storage containers and processing and selling sites of halal food shall be used for special purpose. Where there are conditions, cultural centers (stations) and libraries with $\mathrm{MinZu}$ characteristics should also be established. Some traditional medicine, such as traditional medicine of Tibetan, DaiZu, MiaoZu edc., should also be supported, and we can establish MinZu hospitals, MinZu medical research institutes and development of traditional $\mathrm{MinZu}$ medical science.

- The protection of the language rights of urban $M i n Z u$ groups. Because of the fragmented situation,The $\mathrm{MinZu}$ groups in the city lacks the objective conditions to apply the self- $M i n Z u$ language. In order to protection their language rights, the government can simultaneously establish relevant academic research institutions, strengthen the way of publishing the audio-visual products and books of MinZu.

\section{THE DEFICIENCY AND COUNTERMEASURE OF THE Protection OF SCATTERED MinZU Groups Rights IN THE CURRENT CITY}

The interests of the urban-scattered MinZu groups have been well guaranteed. At the same time, we should also recognize this phenomenon that as more $\mathrm{MinZu}$ groups work, they also begin to gather in the city.This will bring new problems to urban MinZu work. Some new problems have been brought to the protection of MinZu rights and interests. In this regard, we can take the following aspects to protect the interests in cities.

First, relevant laws and regulations should be improved. When the time is ripe, we should make the law on the protection of the rights and interests of scattered MinZu. In the present day, the related issues of the scattered $M i n Z u$ groups are more and more prominent, as some scholars have called for the necessity of establishing the law on the protection of the rights and interests of scattered MinZu as soon as possible. The scholars think that the advantage of promulgating the law on the protection of the rights and interests of scattered MinZu is that, first of all, it can arouse the attention of the society and the government on the rights and interests of local scattered MinZu groups. Because of the population is small, their rights and interests of the scattered MinZu groups are often not due to the attention and concern of the society. The law not only protects their rights, but also prompts the political parties and governments as well as the whole society to pay attention to the MinZu issues, comprehensively promote urban $M i n Z u$ work and safeguard the rights and interests of the scattered MinZu groups. Second, this is an important manifestation of our overall promotion of the rule of law. The rule of law is the basic way of governing governance. The government should also be promoted the work of the scattered MinZu groups in the city under the law. Through the establishment of the law on the protection of the rights and interests of scattered MinZu groups, it can make the city scattered $\mathrm{MinZu}$ rights and interests. The laws also makes the city scattered MinZu rights appeals with the support of the law. Finally, we should improve the legal system construction of MinZu in China. China attaches great importance to the MinZu legislation work, from The Constitution, The Law on Regional MinZu 
Autonomy and administrative rules and regulations as well as the numerous local regulations, autonomous regulations and separate regulations, constitute the $\mathrm{MinZu}$ legal system of China. This system has played an important role in safeguarding the rights and interests of ethnic minorities. As the times change, there are places in these contents of the systems that are not in keeping with the times. Scattered MinZu groups, for example, because of the urbanization process, a lot of MinZu groups will go to cities for job and study. From the changing trend of $\mathrm{MinZu}$ population distribution, the urban population is gradually increasing while the rural population is gradually decreasing. The protection of the rights and interests of the city scattered $M i n Z u$ groups needs to be given sufficient attention. The development of the law on the protection of MinZu rights and interests is the need of the times. [6]

Second, we should change working ideas on the urban $\mathrm{MinZu}$ work, improve the MinZu work governance and modernize the governance system. Xi Jinping pointed out that the government must manage the MinZu floating populationurban in the cities. [7] If we want to protect the rights of scattered MinZu groups in the city, we must abandon the previous kind of paternalistic, big - envelope the management idea. Its governance should be aimed at maintaining the fundamental interests of MinZu groups, and achieving social stability through governance to ensure that they live and work in peace, social stability and order. In the specific way of governance, first, you need to clear the responsibility of the relevant departments, especially with bureaus of $M i n Z u$ and religious affairs in every area. The new situation and phenomenon of urban MinZu groups in this region should be found in time. In order to ensure the correctness of the decision; the existing policy should be revised in time. Second, a strong integrated coordination unit needs to be established. Urban MinZu work involves social security, health care, education, business, security, quality inspection and other aspects. Only by bureaus of $M i n Z u$ and religious affairs in every area are difficult to solve the above problems, so we need to establish a hierarchy covers the functions of the party and government leaders and their specific comprehensive coordination mechanism in the party and government, as a whole to solve related problems.

Third, we should strengthen the rescue of the floating $\mathrm{MinZu}$ population in the city so that its rights and interests can be effectively guaranteed. Urban MinZu groups floating population management is difficult. These people are highly mobile and difficult to manage. At the same time, most of them come from ethnic mountain villages and are not suitable for urban life. Some of them eventually went criminally absent for lack of essential life skills. Some of them have a poor language and then find it hard to find decent jobs in cities. These causes eventually make it difficult for them to integrate into urban life. On the other hand, the government ignores the management of the $\mathrm{MinZu}$ groups and lack of management means and services. Therefore, for this part of the MinZu groups, the first thing is emphasis on thought and we should propaganda MinZu laws and policies in multi-level and multi-channel. Not only the $\mathrm{MinZu}$ floating population understands relevant legal policy, other people also can know related laws and policies. They must abide by the law and take the initiative to integrate into urban life. Cities should also provide these people with the necessary assistance according to the law. In the specific management work, we must establish a sense of service, through the contact system, etc., to promptly solve their employment, diet, religious beliefs, education and other difficulties, and we should actively help them familiar with the urban environment and into urban life.

\section{CONCLUSION}

In summary, it is a new issue of urban management how to solve the problem of urban diaspora minorities appearing in the process of urbanization. It is necessary to provide a good social environment for MinZu groups to guarantee their $M i n Z u$ rights and promote their integration into urban society. It is necessary to promote $\mathrm{MinZu}$ development and ensure the stability of the city. Only through the rule of law, we can change the above ideas into reality and protect the long-term stability of society.

\section{REFERENCES}

[1] China's Ethnic Policy and Common Prosperity and Development of All Ethnic Groups, http://politics.people.com.cn/GB/1026/10126896.html, [EB/OL]. [2017-11-22]

[2] Jiansong Zhang edc.Let the 10 million MinZu people who go out for work and study merge into cities as soon as possible.http://news.163.com/11/0211/10/6SJUDA4F00014JB5.html, [EB/OL].[2017-11-22].

[3] Wu Dahua, National Law, LawPress, China 2013:270

[4] State Ethnic Affairs Commission Policies and Regulations Division.Compilation of exchange materials for national urban ethnic seminar.2010:61.

[5] Article 1 of the Regulations on Urban MinZu Work

[6] Cheng Kunyi. "Scattered MinZu Rights and Interests Protection Law "should be promulgated as soon as possible" - visit the Guizhou MinZu Institute, the Chinese Law Society MinZu Law Research Association executive vice president Wu Dahua", http: //www.fzshb.cn/News/201001/5450.html, June 30, 2015 visit[EB/OL].[2017-11-22].

[7] A New Comment on Xi Jinping 's MinZu Work:the government must manage the $\mathrm{MinZu}$ floating populationurban in the cities. http://news.163.com/14/0929/20/A7BA26CE00014SEH.html, [EB/OL].[2017-11-22]. 